\section{Vision-from a wide mantel}

(The Clarence H. Graham Memorial Lecture delivered at the annual meeting of the Psychonomic Society, St. Louis, Missouri, November 11, 1971)

FRANK A. GELDARD

Princeton University, Princeton, New Jersey 08540

Graham's contributions to visual science are summarized. The emphasis is on his research in color vision, but work on stereoscopic vision is also mentioned.

Let me say straightway how much I appreciate being asked to participate in this memorial exercise for my lifelong friend, Clarence Graham. I had the privilege of being on hand to help out with his initial launching into professional life, even had something to do with arranging his early academic environment, and followed his highly successful career with much interest. The personal involvement is therefore great as we come together to honor one of our number who became an outstanding scientist and whose work will long be a benchmark in his chosen field.

Perhaps we ought to begin by asking just how Graham got into vision. I know that story as only he and I knew it. There were both positive and negative forces at work. On the positive side, I think I can do no better than to quote from an autobiographical sketch he wrote many years later: "I finally became a student of psychology," he says, "and took experimental with Nafe in my senior year. Frank Geldard, two years my senior, was starting work on his doctor's thesis and beginning to recruit subjects and, as it turned out, an experimenter (myself) for his work on light adaptation. I remember that I experienced an almost joyful feeling as I sat in the dim ambient illumination of the dark room timing the stimulus presentation, hearing the clicks and later seeing the data take shape.... That year's activity surely bent the growing branch in a way that has persisted."

The negative side he may well have repressed, but I remember it well. The custom at Clark was to pick a topic for the Master's thesis early in the first year, formulate the problem, and get the apparatus well in hand by the Christmas holiday. Ideally, readings began right after New Year's. The only peychological problem that impressed him was the one on light adaptation, and we talked at length about the possibility of his tackling the analogous one in hearing, the measurement of auditory fatigue to astained tones by a comparison tone procedure. No one had done it. What was needed was a steady-tone generator, the output of which could be rapidly switched from one ear to the other.

Graham and I got busy in the shop with the building of an oscillator; we were, after all, pretty adept at putting receivers. Anyone with any electrical sophistication could do that in the middle ' 20 s. We fired up the WD-12 tubes, wound variometers and honeycomb coils, manipulated variable grid leaks and condensers, but all to no avail. We couldn't get the critter to oscillate, at least with the vigor a well-behaved oscillator should display. I don't have a reliable estimate of the number of hours we spent, only the certain knowledge that Christmas came and went and Graham was little closer to the accomplishment of the measurement of auditory adaptation. When all seemed lost, he avidly adopted a suggestion made by Wolfgang Köhler, who had been visiting Clark the previous year, that someone should find out just how reversible configurations depend for their dominance on angular subtense. He had his apparatus in an afternoon, nothing more elaborate than Bristol board and India ink being entailed. He also completed a throughly competent experiment that has served as the model for countless repetitions in courses in experimental psychology. Moreover, Graham was in vision; he was never to leave it. In the electronic age of only a few years later, he would have ended up in audition.

Having accounted for the way in which it all started, let me go on to tell you about the development of Graham's career in visual science and to explain what must be, for many of you, my cryptic title for this talk.

Some years ago, in the interest of effecting a liaison between those neurophysiological work in the United Kingdom and in America, a noted British neurologist made an extensive series of visits to laboratories scattered all over this country. Mine was the last laboratory on his itinerary before our friend took off for the return trip to England, and I therefore judged that he would now have acquired considerable perspective and would be in a strong position to render an together regenerative-type radio engaged in psychological and overall judgment about the quality of work in America. He was, of course, and he did. "Everywhere I go," he said, "I see beautiful apparatus and techniques of great intricacy and elegance. Everything is impeccably quantized. This variable is being related to that variable with great precision. But, if you will forgive me, there is something important lacking. I think it is that you do not have wide enough mantels in this country to put your feet on."

Clarence Graham never suffered from this deficiency. Indeed, the lasting image I have of him, whether in his office at Schermerhorn or in the back coffee room off the shop at Clark, has him sprawled out with his feet on the table, his eyes riveted on nothing more attention-demanding than the empty sky out the window, but with the little gray cells clearly being mobilized. This propensity for thinking things through before committing himself to the busy work of setting up equipment and experimental schedules was an abiding characteristic. It showed up early. Two years after the doctorate he had published a thoroughly ingenious paper on the possible role of inhibition in color contrast, and two years after that he not only produced the much - debated paper on "Psychophysics and Behavior" but had contributed his chapter on visual neural correlations to the Murchison Handbook of General Experimental Psychology. This was not just a factual recital. It was the first serious attempt to assess the role of neural interaction in all manner of visual processes. Of late, this topic has come back to near the center of the stage. Indeed, it is as exciting a problem, not only in vision but in the other senses as well, as may be found in the entire current sensory psychophysiological literature.

It was always the same. Graham never undertook a project to "relate this variable to that one" or to give a pretty piece of apparatus a workout. When he and his subsequently distinguished student, Lorrin Riggs, undertook in the middle ' 30 s to establish the visibility curve of the white rat, it was not to show off an elegant bit of recording technique, albeit they used the Edelmann string galvanometer first acquired by Ralph Lillie for his iron-wire nerve model experiments, or just to synthesize a smooth curve of visibility for the beast. Meaning could be given to the whole exercise through comparison of the obtained visibility values with the preexisting curve of Hecht and Williams for visual purple. They thus could conclude about the probability that rats did not have color vision, 
agreeing at the time with the classic behavioral data of Watson and Watson and those of Munn. The fact that a whole host of animal behaviorists were subsequently to complicate the problem endlessly is pretty much beside the point. And the fact that Lillie's string galvanometer was next to be pressed into service by Graham, Kemp, and Riggs on the eye of the pigeon, well known to have color vision, with the result that it, too, gave only what appeared to be a rod curve, is likewise beside the mark. The point is that principles that mattered were at stake whether the right answers were immediately forthcoming or not.

The years 1934 to 1940 , a period partly spent at Clark and partly at Brown-and, in any case, which represented a general confluxion of Worcester and Providence talents in that 44 miles separating these citadels could not keep apart the research team of Graham, Eddie Kemp, Bob Brown, and Lorrin Riggs. These, plus some others more especially connected with Brown-Fred Mote and Neil Bartlett come particularly to mind-joined in what was a really remarkable effort of a systematic kind. Selig Hecht had just published his impressive paper on visual intensity discrimination, and it raised some questions answerable only in the laboratory. Hecht's theory concerned itself exclusively with the initial photochemical event, given the baseline of a balanced equilibrium, brought about by the addition of $a$ just-discriminable intensity increment, $\Delta$ I. Hecht held that a constant photochemical decomposition must accompany the introduction of $\Delta I$. First, Graham, Brown, and Smith, then, in a much more searching fashion, Graham and Kemp put the question: "What happens if the duration of $\Delta I$ is lengthened; what if we do not deal exclusively with initial photochemical events?" With durations varying over a range of 2 to $500 \mathrm{msec}$ and intensities standing in a ratio of more than 100,000 to 1 , Graham and Kemp worked out the detailed relations connecting flash durations and discriminable increments and showed that two master expressions held, depending on whether the increment fell short of or exceeded the critical duration. Below the critical duration, itself a function of intensity (as not everyone seems recently to recognize), the Bunsen-Roscoe law governs the photolysis of $\Delta I$; at durations greater than the critical one, the reciprocity law is superseded by the expression, $\Delta I=K$. Thus Graham and Kemp were able to amplify Hecht's intensity discrimination theory to avoid the special case basic to it, and they concluded, most generously, as it seems to me: "Hecht's theory accounts for the data of this experiment if it be assumed that brightness discrimination is determined by a constant amount of photolysis."

Reciprocal relations between intensity and area were next to be attacked. "Attacked" is the mot juste; this is a century-old battleground. Lying about are two notable pieces of debris: Ricco's law, originally thought to hold only for the fovea but later found to apply to small visual fields wherever situated, and Piper's law, originally supposed to be a peripheral phenomenon but which was probably so judged because it applied only to large fields, and you can't have these confined to the fovea. In any case, no one ever supposed that the two laws, which differ by only a radical sign, were anything but approximations. Graham, Brown, and Mote thought there might be other things wrong with them and noted that experimental control, in much of the classical work, left much to be desired. For one thing, the data were generally sparse, and really small fields had never been used. For another, field size had often been varied by the simple-minded procedure of moving the observer to and away from the stimulus patch. Then, there was the difficulty that nonequivalent retinal test spots had been used in some experiments; also, fixation conditions were often quite inadequate. The Brown team took care of all these, employing fields ranging from something under $2 \mathrm{~min}$ to over $25 \mathrm{deg}$ in subtense, distributing them wisely and insuring uniform adaptation and strict fixation. They were able to show, quite elegantly, that intensity thresholds follow a typical course with increase of area, whether the fovea or periphery is involved. Small areas bring high thresholds. Areal increase brings about a threshold decrease up to a limiting value. This is about $1 \mathrm{deg}$ in the fovea and $10 \mathrm{deg}$ in the periphery. The factors at work to effect these empirical relations are, in part, simple integration of elemental excitatory processes and, in part, facilitatory and inhibitory interactions of specifiable character.

This work, with Brown and Mote, was done with white light as a source. Two additional experiments, both in company with Neil Bartlett, were natural followup efforts. One was to extend the measurements to extreme red and violet lights. In brief, the previously obtained relations for white were again found to hold. The other raised the important question of whether the same tradeoff relation could be expected at levels well above absolute threshold.
What role would area play in foveal intensity discrimination? As with some of the earlier problems, one might suppose that the literature would yield some answers. This is not exactly a neglected topic, after all. But it has to be remembered that there is a 1-deg limit to be considered; also, unless one wishes to contend with the complications introduced by the critical duration, it would be well to keep exposures brief. Where do you find visual intensity discrimination data with adequate areal variation below $1 \mathrm{deg}$ and with exposures well under 100 msec? At that time, nowhere.

Graham and Bartlett set out to remove the deficiency. They used six circular patches subtending from 4 to $56 \mathrm{~min}$ in angular diameter and restricted exposures to a constant 30-msec duration. Adapting intensities ranged over $4.6 \mathrm{log}$ units. It turned out that, for any particular area of the test patch, the Weber fraction, $\Delta I / I$, had a high value for low intensities and a low one, which approaches a limit, for high intensities. If intensity is held constant and area is varied, $\Delta I / I$ is large for small areas and smaller for large ones. Two hypotheses, one calling for spatial interactions among active units within the stimulus area, the other providing the retinal photochemistry to go with it, were invoked to account for the results. That both the facts and the theory have currency is attested by the masterful treatment given them by Connie Mueller and John Lott Brown in the book that will long remain a living monument to Clarence Graham, Vision and Visual Perception.

There were some less formidable but nevertheless significant minor studies done within the span of years we are considering, the late-Clark/early-Brown era. Two of these, Graham and Cook, on acuity as a function of time and intensity of exposure, and Levine and Graham, on afterimage latency as a function of illumination of an area contiguous to the test area, obviously fall within the general pattern of work of the period, as does also the not-so-minor study (judging by the frequency with which it is cited these days) of Graham and Margaria on area and intensity-time reciprocity in the peripheral retina. There were also some independently published studies clearly falling within the program, such as Bob Beitel's experiment on interaction of subliminal stimuli and Harry Karn's research on the time-intensity relation in the fovea as a function of test area.

A fitting milestone for the work of the late ' 30 s was the presentation, at the Rutgers meeting of the Society of Experimental Psychologists, in 1941, of the Howard Crosby Warren Medal 
for "distinguished research in vision." The award was a popular one on an occasion made the more memorable by an after-dinner talk by Robert Yerkes, who warned us of the scandalous neglect, since the end of World War I, of problems of interest to the military, those of personnel selection, classification, and training. Before the end of the year we were to carry our ignorance into World War II.

Something of Clarence Graham's versatility, already in evidence from his early aseociation with Bob Gagné on the problem of latency of running behavior in the white rat-many of you will think of the Graham-Gagne runway-is attested by his activities during the war years. As a member of the Applied Puychology Panel of the National Defense Research Committee, he tumed to problems of gunfire control, especially hoight finding and binocular ranging, a tak in which he was ably anisted by such colleagues as Wilf Brogden, Bill Kappauf, Bill Biel, and Doug Ellson. Some younger, recent PhDs (Neil Bartlett, Fred Mote, and Bill Verplanck) were involved, as were many of the graduate students at Brown (youngsters like Connie Mueller, Dick Solomon, Ftiot Stellar, and some others). This kind of work seemed not too unrelated to other visual problems, but it would be more difficult to find the link between vision and Graham's other chief $w$ artime project-the development, with Walter Shipley, of a personal inventory to be used in the detection of emotionally unstable naval personnel before they got into the pipeline for training as submariners. Perhaps he was beginning to develop the interests of the man he was shortly to succeed, Robert Woodworth, or perhaps (as he himself said) his peychoanalysis of the late ' 30 s was beginning to get to him.

Academic rebuilding in the year immediately following the war brought about all manner of changes. With suddenly inereased demands for expanded staffs and especially the provision of leadership for them, there were many moves. Established departments were raided; and the more prestigious of them showed heavy turnover. Hunter's Brown department, well recognized as outstanding in experimental peychology, was particularly hard hit. However, it was with Walter Hunter's bleasing that Graham moved on to Columbia to take the chair vacated by Woodworth. Here was obviously a position of great challenge and opportunity and, with Hecht and his cohorts holding forth in the nearby Physics Building, especially attractive to a visionist. In Graham's first year at
Columbia, he and Hecht gave a seminar together, an exhilarating experience for both but unhappily terminated by Hecht's lamentably early death at the end of that year.

Teaching duties and research direction blended into a busy but happy period. With the huge postwar influx of students in 1946 and continuing for another five years, Graham found himself with eight to 10 graduate theses on his hands at any one time. He had inherited Prof. Woodworth's famous course in Experimental Psychology in which he empharized sensation and perception; after all, there were Keller, Schoenfeld, and others to care for learning. I wonder whether his students dubbed his course "The Bye"; mine at Virginia called my experimental coure "The Eye and the Enr," deapite what seemed to me an unconscionable amount of material on learning and memory.

Graham's research, beginning in 1947 and for many years thereafter, was chiefly on color vision and must have been influenced both by Hecht's penchant for problems in this area and that of Graham's colleague, Yun Hsia, who had been with Hecht as a postdoctoral fellow. The two, Graham and Hsia, published nearly a score of papers as joint authors. They were inseparable companions in research until Haia's death in 1968.

Beginning in the late $40 \mathrm{~s}$ and continuing with high output for 20 years, Graham and Haia (and many others, students and associates) pursued the problem of color sensitivity and color blindness. Some studies were unique by reason of their subject matter, studies of abnormal color vision chiefly. Others were revolutionary for color theory.

At midcentury, the evidences were accumulating that not all was well with clasical color theory. Indeed, not all was well with basic color fact. Since 1924, we had lived with the so-called ICI luminosity function, a smooth, symmetrical curve with a peak at $555 \mathrm{~nm}$ representing averaged data for spectral luminosity derived by three different methods: brightness comparisons of spectral samples against a standard, step-by-tep brightnees matches of narrow-width samples throughout the spectrum, and (more questionably) intensity adjustments that would just smooth out succesively presented samples in a flicker photometer. Several measurements of spectral luminosity by thoroughly qualified experimenters suggested a jointed character of the curve. The blue end of the spectrum had a hump in the region of 460 , the red end one near 600 . With the absolute threshold method and aided by the high-precision double monochromator inherited from Hecht-the one on which the now-classic quantum study of Hecht, Shlaer, and Pirenne had been done-Graham and Hsia found that the luminosity curve is indeed a dougle-humped one. The correspondences among five observers are remarkable. The average curve peaks at 550 and has prominent perturbations around 460 and 600 . Also, in agreement with Wald's earlier data and those of Stiles, the standard curve greatly underestimates luminosity in the short wavelengths.

This determination of normal chromatic sensitivity was really only the backdrop for what proved to be a more exciting subject on the color stage, for it was anomalies of color vision that soon came to preoccupy Graham and his coworkers. In particular, he was to devote a large segment of the time remaining to him to the careful study of the extraordinary vision of a young woman, discovered in a laboratory class at Barmard, who possessed one normal eye and a dichromatic one. She had been instructed, in a dart-throwing experiment in which her right eye was occluded, to aim for the "red target." As in the famous 18 th century case, the first recorded one in the annals of color blindness, in which Mr. Harris, of Cumberland, England, was perplexed by an inquiry about a child's lost red stocking (and which he regarded as being completely described by its being called a stocking), the young lady questioned the instruction until, freed of her right-eye blindfold, red replaced yellow and the message was finally correctly received.

Seven different visual functions were throughly investigated by Graham, Hia, and several coworkers; there eventuated more than a dozen papers touching on or central to the topic of unilateral dichromatism. If these had simply provided alternate accounts of a single interesting case, one could question the spilling of so much ink, but, as always, Graham characteristically had his feet on the mantel. Questions vital to color theory emerged as the study went on, and, before it was finished, some very old questions indeed found answers and new contributions were made to method.

Functions tested were: threshold spectral luminosity, critical fusion frequency of flicker, binocular brightness matches, complete color mixture curves for both the normal and dichromatic eye, color naming, the normal eye checking on the color-blind one, wavelength discrimination for each eye, and binocular color matches (to 
supplement the color-naming experiments). A detailed account of each of these functions is hardly warranted here; as I have said, the literature is commodious. However, we ought to see how these manifold measurements changed things for interpretation of the color mechanism.

Graham's unionular dichromat fits exactly no standard classification of color defect. Her left eye is more nearly deuteranopic than anything else. In the extreme red, it is normal with respect to luminosity but there is a loss running from 625 to 430 , more than for most deuteranopes. Critical flicker measures, show the same, precisely. The red is normal, but there is a slight loss in the orange and varying amounts of it in the remainder of the spectrum. Green shows the greatest reduction. When it comes to color mixing by the usual additive method, the defective eye matches all narrow bands of the spectrum with some mixture of only two primaries, 460 and $650 \mathrm{~nm}$. What does this eye see? In the spreadout spectrum, there is a gray neutral point at about 502 . Below this all is blue, matching in hue wavelength 470. Above this all is yellow, matching 565. Thus far one would say, "clearly deuteranopic." But if you add the wavelength discrimination data, complications set in. While the picture between 500 and 750 is what would be expected of a deuteranope according to both Pitts's and Wright's measurements as well as those of the Columbia laboratory, this eye is too sharp in its wavelength distinctions in the violet.

But simply to add another deviant eye to a great catalogue of them, many of which deviate because they were measured badly, would hardly be research in the Graham manner. What did this line of work accomplish? It should be obvious that the sheer advances in measurement techniques were considerable. Also, the gathering of so many coordinated data on a single visual system were of great aid in evaluating disparate methods. More importantly, however, it led to what must be considered a real advance in color theory.

Since Koenig's time, there have been two main lines of explanation for the symptoms of dichromia. One of these, traceable to Thomas Young's original hunches, is that protanopia and deuteranopia are the results of loss or perhaps suppression of one or another of the three fundamental color processes; dichromia is a deficit phenomenon. The other, espoused especially by Aitken, Leber, and Fick in the early 1870 s but most strongly supported by Fick, held dichromia to result from incomplete differentiation, in the course of development, of the red and green primaries, but with full retention of the neural connections and reporting procilivities for both types of cones. Protanopia and deuteranopia, under this interpretation, become essentially substitution phenomena. Nothing is lost in these defects; all cones should be functioning, but the red-receiving substance should replace the green in deuteranopia, while green should substitute for red in protanopia.

The Graham-Hsia measures of absolute energy thresholds of dichromats very importantly relieved the problem of relative luminosity coefficients, and demonstrated clearly that deuteranopes do lose luminosity in the green and blue. Protanopes lose it in the red, as had long been appreciated. These are deficit phenomena. Moreover, the flicker work and that on binocular brightness matches showed that such deficits are still in evidence at luminances well above absolute threshold. So Fick must have been wrong. But does that make Young right? Not necessarily. What the impasse does is to raise another question, one that Graham confronted with more than a little elevation of the pedal extremities.

The question has to do with the origin of yellow. Yellow, a mixture of red and green, is still retained by both kinds of dichromats, despite their failure to distinguish between red and green. Indeed, we saw that Graham's uniocular dichromat sees all spectral samples above the neutral point as yellow. How, then, with a significant loss in the green, for the deuteranope, and a similar one in the red, for the protanope, could yellow come on the scene? Graham's solution was to borrow from Fick only to the extent that the red primary and the green primary become identical. Red moves towards green in absorption characteristics; green moves towards red. They become identical, and both of them signal central yellow. To account for differences between protanopes and deuteranopes it is assumed that there are appropriate absolute sensitivity changes that would carry with them luminosity emphases towards either the shorter or longer waves.

This formulation has about it the earmarks of a good hypothesis in that it agrees with the best existing facts and yet is eminently testable. Graham got only a certain distance in accumulating the relevant cases, but many yet to come, following the blaze marks of his trail, will do so.

His own interest in color anomalies was piqued by two other notable cases of color defect. One was that of a colleague, Fred Stephan, who had suffered a vascular accident of one eye that left vision somewhat impaired in central 18-deg area of that eye. Ther were, however, "islands" of lesse blurring in the region. Portions of th scotomatous area proved to hav disturbed color vision. Binocular hu matches, luminosity functions, colo naming, and neutral ban determinations all pointed to this as at acquired tritanopia. A neutral poin occurred at 569 ; longer waves matche a reddish orange of 617 , while shorte ones matched a blue of 478 . This $i$ not far from the classical picture o congenital tritanopia. The distinctiv, feature added is a significant loss 0 . luminosity centering upon the neutra point. The study added much to ov understanding of this rare kind of color defect, especially telling u something of the nuances of colo naming that may go on in such an ey when subjected to systematicall varying illumination.

The other extraordinary case was that of a young woman, previously diagnosed totally colorblind and reduced to pure rod vision. However these judgments had been based on thi complete absence of hue distinction. at low photopic levels and, in addition to the expected photophobia and miner's nystagmus present from infancy, the fact that her dark adaptation curve showed only a singla branch, that characteristic of rod vision. Graham, Hsia, and two forme students undertook to examine he further in the light of the additional finding that there was some evidency for at least rudimentary fovea functioning. Tests at relatively high luminances revealed a remnant $o$ color sensitivity. In the fovea, a tritan defect was superposed on the reduction of cone sensitivity. No cone activity could be found in the periphery, even at very high adapting luminances. Here, then, is yet anothel variant of monochromia, one taking its place alongside some other baffing phenomena associated with colol reductions.

I have dealt at some length with problems of color and color theory almost as if this had been Clarenct Graham's sole concern. It was not, of course, but in my view it is the domain of his most important and lasting contributions. It seems that he mighi easily have taken as his guide for action the strictures of Selig Hecht who, commenting on the plethora o1 conflicting and irreconcilable colo: theories in the early " 30 s, said: "The failure to realize this ideal [the synthesis of color theories] has nol been for want of ideas.... What has been lacking has been a certain objectively critical perseverance to sort out these ideas and to follow through their quantitative implications ... 
more is to be gained by the rigorously quantitative treatment of a small field in a concrete manner than by the multiplication of vaguely general and obviously inadequate theories, of which there are already far too many."

Second only to the color work was Graham's abiding interest in geometrical optics and the perceptual problems surrounding this area. Indeed, on two important occasions, he turned to this topic as his chief theme. The first was in March 1963, when the Optical Society of America awarded him the Tillyer Medal for "... his many valuable researches in visual science, ... his outstanding leadership,... and his success in training new scholars." In accepting the award, he chose to talk about real and apparent movement, reviewing the chief parameters of both and showing the analytical similarity of the two. The trapezoidal window and Korte's laws became congenial bedfellows on this occasion, helping to carry the main point, which concerned the ubiquity of movement phenomena in everyday experience and the importance of its becoming more central to visual theory. A few years later, when Graham was the recipient of an American Psychological Association Distinguished Scientific Contribution Award, he expanded on the topic of depth and movement, assembling many new data on monocular movement parallax, a function the measurement of which reduces to the determination of threshold differential angular velocity and yields remarkably low thresholds (values of the order of 30 to $60 \mathrm{sec}$ of arc per sec). Several of Graham's most recent graduate students were encouraged to push on in this field of movement perception, stimulated by neurophysiological discoveries concerning motion in retinal receptive fields as well as by their sponsor's systematic speculations.

Those of you who followed Clarence Graham's career will know that not all of it was spent in the laboratory nor yet all of it on the domestic scene. Travels to the Far East and to Europe, on several occasions, had him in the role of scientific ambassador, and there could have been no better choice for carrying out this function. Nor were these journeys unconnected with the science of vision. In a single year, 1952, he presented a seven-week seminar on vision and allied topics at Kyoto and, on the heels of this, began a one-year sojourn at the London Branch of the Office of Naval Research, by all odds our best medium of scientific intercommunication in Europe. If points of special liaison were such laboratories as Granit's at the Karoline Institute, Toraldo di Francia's at the Institute of Optics at Florence, and Michotte's at Louvain, it should not surprise us greatly. Much lasting good was accomplished by such activity. Indeed, it is not too much to say that Graham's visits to a score or more of active European laboratories of psychology, physics, and physiology still produce reverberations, as do those made to a dozen Japanese psychological laboratories seven years later. In many instances, they opened the door for highly fruitful interchanges. This is something America in the 1970 s cannot afford to ignore.

There is another whole story that might be woven around the career of Clarence Graham. It would have to be labeled something like, "Graham, the Theoretician and Systematist." It would take as its text any of several available quotations from his writings. Here are two that might serve: (1) ". . the use of the word 'sensory' as different from 'perceptual' can be justified only as a matter of convenience, not of content [Graham and Ratoosh in Koch, Vol. IV]"; (2) "Analysis of the classes of stimulus-response functions concerned in perception indicates that the study of the latter topic becomes coextensive with the general study of behavior [Graham, EPA presidential address, 1956]." There is nothing obtuse or unrepresentative about these selections. Graham meant them, and from such statements, you would be right if you concluded that, relative to some of the doctrine with which he was imprinted, he was a very considerable radical in psychological theory. But your conclusion would not be admissible until you had done as he would have done, defined nearly every term in that statement, certainly the words, "radical," "theory," and, as I seem increasingly to believe it must be these days, the word "psychological." A radical, then, in psychological theory, but one with his feet squarely on the mantel. 